Article

\title{
How Can Travel Agencies Create Sustainable Competitive Advantages? Perspective on Employee Role Stress and Initiative Behavior
}

\author{
Leo Huang ${ }^{1,2}$, Kuang-Yu Chang ${ }^{1, *(1)}$ and Yu-Chen Yeh ${ }^{1}$ (1) \\ 1 Graduate Institute of Tourism Management, National Kaohsiung University of Hospitality and Tourism, \\ Kaohsiung 81270, Taiwan; Leo@ydu.edu.tw (L.H.); shane921tw11@gmail.com (Y.-C.Y.) \\ 2 Department of Leisure Management, Yu Da University of Science and Technology, Miaoli 361, Taiwan \\ * Correspondence: C0211003@stu.nkuht.edu.tw
}

Received: 13 May 2020; Accepted: 31 May 2020; Published: 3 June 2020

\begin{abstract}
In this study, we aimed to explore the importance of the roles of stress and organizational citizenship behavior toward market orientation in travel agencies from the perspective of organizational culture, and to provide practical suggestions for travel agencies' human resources. We focused on investigating the relationship among market orientation, competitor orientation, and inter-functional coordination, role stress, conflict, ambiguity, and inter-enterprise organizational citizenship behavior. Under an enterprise strategy, the employee behavior model uses role stress and organizational citizenship behavior. Partial least squares (PLS) modelling was used to investigate the hypotheses in this research. We found that travel agency employees who focus on market-oriented strategy are able to reduce stress and promote the growth of organizational citizenship behavior within the enterprise. The results showed that reducing role ambiguity has no significant impact on organizational citizenship behavior. Adopting an accurate management strategy will reduce employee role stress and promote organizational citizenship behavior, thereby constructing a positive organizational culture and continuously creating competitive advantages, providing a strategy for the sustainable development of travel agencies.
\end{abstract}

Keywords: organizational culture; customer orientation; competitor orientation; inter-functional coordination; role stress; organizational citizenship behavior

\section{Introduction}

Role stress affects employees' attitudes and behavior [1]. High employee role stress reduces organizational citizenship behavior [2-4] and enterprise performance is affected by whether employees perform organizational citizenship behavior [5]. When employees show positive initiative behavior while working, they can build positive organizational culture through market orientation and foster sustainable development capabilities [6].

Role stress is a factor that should be considered by enterprises. When employees perform two or more roles, they cannot fully understand all the expectations. Therefore, they are unable to perform the appropriate behavior and gradually experience role conflicts. When employees lack clear authorization or instructions based on job responsibility and power, they are unable to fulfil role expectations and instead perform individual role behaviors. This may lead to role ambiguity. Therefore, if enterprises do not attach importance to the role stress experienced by employees, the organization may be negatively impacted. Conversely, if employees are dedicated to a market-oriented strategy, the stress generated by working can be reduced [7].

Market orientation is one of the strategies adopted by many enterprises. It enables enterprises to perform and create sustainable competitive advantages by satisfying customer needs, understanding 
competitors, and smoothly implementing organizational procedures in the competitive market $[6,8]$. The tourism industry is no exception. Travel agencies adopt market orientation to a high degree and understand customers' needs and the status of competitors, strengthening the organizational internal corporation mechanism, reducing employees' role stress, and encouraging employees' initiative within organizational culture, with the aim to improve the organization's operation sustainability and competitive advantages.

The travel agency market in Taiwan is characterized by high degrees of competitiveness due to the low entry barriers. According to the statistics of the Tourism Bureau, there was a total of 3989 travel agency companies and branches in Taiwan as of March 2020. In such a limited market, practitioners must fully use the enterprise's internal resources to continuously meet customer needs and to simultaneously understand competitors' actions. Thus, the market orientation strategy is used by numerous travel agencies to produce sustainable competitive advantages and promote sustainable operations to build and grow the enterprise culture. A market-oriented strategy reduces employee role conflicts and role ambiguity. A small number of studies have focused on the impact of negative factors on organizational citizenship behavior [9-12]. Thus, we explored the relationships of market orientation, role stress, and the behavior of organizational citizenship.

Here, we explored whether market orientation can reduce travel agency employee role stress and consequently, foster organizational citizenship behavior. Therefore, the purposes of this study were threefold: (1) to discuss the impact relationships between market orientation and role stress; (2) to understand the relationship between role stress and organizational citizenship behavior; and (3) based on the results, to discuss and propose research and practical suggestions. The remainder of this paper is structured as follows: Section 2 provides the theoretical background of this study, Sections 3 and 4 illustrate the use and analysis of the research methods used in this study as well as the results, and Section 5 provides conclusions and implications.

\section{Literature Review}

\subsection{Influence of Market Orientation on Role Stress}

Market orientation is the integration of organizational culture [13]. Therefore, the implementation of market-orientation processes over some time gradually forms the organizational culture and a sustainable competitive advantage [14]. Market orientation refers to a specific form of organizational culture, which is a characteristic of an organization that sustainably delivers value to customers. Market orientation involves three behavior elements (customer orientation, competitor orientation, and inter-functional coordination) as well as two decision criteria behavior elements: permanence and profitability. Due to stress on information from external customers and competitors, market-driven organizations can develop market positioning based on knowing customer needs in advance via innovative capabilities and rapidly responding to customers [15].

Market orientation explains the enterprise's focus and adjustment to movements within the external market environment, which displays the enterprise's ability to cope with the external environment and can considerably benefit the enterprise, for example, by understanding customer needs, improving customer satisfaction, and expanding market share to increase profits for the enterprise. Information exchange between internal departments and employees can enhance the sense of identity and cooperation between departments and employees as well as improve the emotions and attitudes of employees. Market orientation is based on market research, customer interviews, and so forth, which help to grasp market trends (competitors) and changes in customer needs in advance, propose appropriate response strategies, and reduce product failure rates [16,17].

From the information perspective, the collection of market information includes customer needs, competitors' strategies, development, and other factors that affect the current market situation. In addition to collecting market information through the personnel of each department, the organization can assist with information transmission and circulation among organizational departments to improve 
the quality of decision-making as well as help develop the enterprise [18]. From the perspective of market-orientation behavior, customer orientation involves understanding the target customer, organizational customer market segmentation, focusing on strategies to provide buyers with superior value, and effectively improving the organizational profitability. Competitor orientation refers to an organization that is familiar with the status of current and potential competitors, including short-term advantages and disadvantages along with the permanent abilities of competitors, for which a response plan must be effectively formulated. Inter-functional coordination underlines the enterprise's overall resource integration and use to provide customers with better value, avoid employees from different departments and strata acting independently, and helping align departments in the same direction to avoid wasting human resources [19].

Many market-orientation studies have focused on the consequences. For instance, customer orientation affects the sustainable development of the organization's financial aspects, and inter-functional coordination promotes the sustainable development of the enterprise's management hierarchy [6]. Furthermore, many studies have explored the effects of market orientation on organizational performance or employee behavior [20-22]. Other studies related to market orientation emphasize external markets. Market information is generated, digested, and used by internal employees [23]. If an enterprise cannot confirm whether employees are satisfied with their work, sustainable development will be difficult [24].

The episode model is divided into role sender and focal person. The role sender has expectations about how the focal person should play the role. The actual behavior of the focal person is observed, felt, and commented upon to determine whether the behavior meets the role sender's expectations. After evaluation, the role expectation is formally or informally explained to the focal person, which affects the desired performance of the focal person. If the expectation of the role sender is conflicted or ambiguous, the focal person will experience role ambiguity or role conflict from an objective point of view. This kind of role expectation will place pressure on the focal person and affect their behavior.

Role stress theory divides roles into role conflict and ambiguity. Role conflict refers to working in an organization where the person cannot simultaneously meet the inconsistent requirements or expectations of multiple roles. Role ambiguity refers to inappropriate or incomplete information and knowledge, so the person cannot meet the expectations for appropriate behavior [25-27]. Role stress can be divided into objective facts and subjective experience. The objective facts refer to the environment in the organization having certain factors that are not conducive to the role, which leads to undesirable characteristics. In addition to working tasks, organizational structure, role requirements, job characteristics, and the actual organizational environment all affect the role expectations of the role sender. Organizational factors produce role stress. Subjective experience is caused by the role, including one's own experience, psychological history, personality traits, and other factors, resulting in the role itself to produce a negative perspective of the objective environment [25].

Research on role stress has shown that conflict and ambiguity of roles are the reasons for reducing work efficiency, increasing tension, and labor turnover [28]. Numerous negative correlations of role pressure with working attitude, job performance, job satisfaction, and organizational commitment have been reported [8,29-31]. Therefore, higher role stress has negative impacts on the organization, such as decreasing turnover and reducing productivity as well as working efficiency [32]. In terms of the factors pre-influencing role stress, studies have shown that factors such as leadership style and organizational climate can generate employee role stress. Notably, studies have reported that an influential relationship exists between market orientation and role stress [33-35], but positive and negative effects exist between the concepts of market orientation (customer orientation, competitor orientation, and inter-functional coordination) and role stress (ambiguity and conflict of role). There is still no consensus; therefore, it is essential to confirm correlations between market orientation and role stress.

Based on constructions of market orientation and role stress, the organizational structure of Taiwan 's travel agencies, ranging from simple structures to matrix structures-regardless of the low 
formalization in the simple structure and the high degree of centralization, which lead to unclear power and responsibilities, job conflicts caused by the specialization of the bureaucratic organization, reductions in employee resilience, and difficult coordination of the departments of the matrix structure organization-may cause role conflicts and ambiguities. Therefore, in the tourism service industries that focus on emotional labor and initiative, role stress directly affects employees' performance, thereby reducing the sustainability of operation abilities and negatively impacting any competitive advantages. When a travel agency adopts a market orientation, the employees' stress should be reduced. Therefore, the structural correlation between market orientation and role stress is discussed in this study.

From the viewpoint of competitive advantage, market orientation can be regarded as the most effective organizational culture for maintaining long-term and mutually beneficial relationships between customers. To create excellent customer value and sustainable competitive advantages, an enterprise attaches importance to customer orientation, competitor orientation, and inter-functional coordination, which are necessary organizational cultural behaviors.

Firstly, from the perspective of customer orientation in travel agencies, the starting point is satisfying customers' needs. Through market-orientation behavior tactics, travel agencies can fully understand the unique value of products in the customer's mind and predict customer needs. Studies have revealed the relationship among customer orientation, role conflict, and role ambiguity [36]. Using a customer-oriented strategy, a travel agency will provide employees with a clear task direction and ensure employees understand the role's tasks, thereby reducing the inconsistency between role expectations and requirements, and avoid ambiguity about the perception of the role's tasks. When employees try their hardest to meet customers' needs, it is less likely to cause employee conflict and ambiguity of role [37], with a negative effect between role stress and customer orientation, which means that when employees feel stressed due to work, the belief in the need to satisfy customers decreases [33,34]. Therefore, travel agencies adopt a highly customer-oriented strategy, which lowers employee conflict and role ambiguity. Based on the above, the following hypotheses were made:

Hypothesis 1: Customer orientation negatively impacts role conflict.

Hypothesis 2: Customer orientation negatively impacts role ambiguity.

Competitor orientation enables organizations to understand the current status of competitors and potential competitors, including short-term advantages and disadvantages and long-term capabilities. Therefore, enterprises can use strategies to deal with competitors. For example, sharing competitors' information from sales personnel, discussing competitors' strategies from top managers, and responding quickly to competitors' strategies provide opportunities for acquiring competitive advantages. Past research has explained that competitor orientation has a negative impact on role conflict and ambiguity [38]. Employees feel stress when they are uncertain [39]. Therefore, adopting a competitor-orientation strategy enables practitioners in travel agencies to obtain clear and consistent task instructions from role senders as well as understand the task direction of a competitor's orientation strategy, reducing the practitioner's sense of uncertainty. We hypothesized that travel agencies adopt a highly competitor-oriented strategy that reduces employee conflict and role ambiguity.

Hypothesis 3: Competitor orientation negatively impacts role conflict.

Hypothesis 4: Competitor orientation negatively impacts role ambiguity.

Inter-functional coordination emphasizes the company's overall resource integration and use, provides customers with excellent value, and prevents employees from different departments acting independently. This coordination helps to align each department in the same direction and prevents the wasting of human resources. 
Research has shown that enterprises adopting a high level of inter-functional coordination reduce employee role ambiguity and role conflict [34]. Therefore, when travel agencies integrate internal resources and strategic direction, internal consistency can be achieved within the enterprise, which enables the role sender to provide clear and consistent task expectations, ensuring the employee understands the task instructions more clearly to reduce conflict and role ambiguity.

Hypothesis 5: Inter-functional coordination negatively impacts role conflict.

Hypothesis 6: Inter-functional coordination negatively impacts role ambiguity.

\subsection{Influence of Role Stress on Organizational Citizenship Behavior}

Numerous studies have found that stress has a negative effect on individual attitude and behavior [2,3], and employee enterprise behavior is highly correlated with enterprise performance. Therefore, employee initiative is one of the positive behaviors valued by enterprises. Organizational citizenship behavior refers to the initiative activities of employees in implementing innovation and acting beyond their role description, such as assisting colleagues, providing advice, self-enrichment, and creating an external environment that benefits the organization by exceeding the role and the behaviors that contribute to organizational goals [40]. Organizational citizenship behavior can be explained through three aspects: social exchange theory, psychological contract perspective, and collaborative relationship perspective. Based on social exchange theory, there are various reasons in society for integration and communication between people, but if a connection forms, each provides emotion, admiration, love, and so forth, which includes money, remuneration, labor services, etc. [41]. From the perspectives of a psychological contract, when an employee thinks of the obligation to form a psychological contract, they hold positive emotions and recognition and these are manifested in organizational citizenship behavior. Conversely, when an employee is aware that the organization has failed to reach a psychological contract with the employee, organizational citizenship behavior is inhibited [42,43]. When an employee and an organization establish synergistic relationships, it affects their satisfaction and organizational commitment and the employee takes civic responsibility for the organization. This kind of collaborative relationship based on mutual affirmation, trust, organizational commitment, and common values is inspired by employee behavior as well as a willingness to contribute their efforts to collective benefits [44].

Employee initiative in the organization will improve organizational performance. Good organizational performance is difficult to achieve when employees only perform in accordance with the organizational rules. Therefore, to operate effectively within the organization, in addition to being willing to participate and stay in the organization as well as achieve tasks that meet specific roles, employees must be innovative and initiate activities beyond their role's description [45].

Studies have focused on understanding pre-factors affecting organizational citizenship behavior and expectations that improve performance through organizational citizenship behavior [46-49]. Most studies have discussed the positive factors that affect organizational citizenship, including trust, job satisfaction, organizational commitment, psychological contract, exchange between mentors and employees, knowledge sharing, and so forth. These factors positively affect employee organizational citizenship behavior [50-52]. The research showed that when employees have a strong perception about belonging and identify with the organization on a psychological level, the probability of showing organizational citizenship behavior is high [53,54].

The high homogeneity of tourism products highlights the importance of service staff initiative. In practice, travel agencies standardize services through standard operating procedures (SOPs), but tourism products are affected by the external environment, and the customer value provided by travel agencies is ensuring a good experience. If the employee service process relies too much on SOPs and lacks initiative, the service process is too rigid. Therefore, if the employees experience role 
stress, especially focusing on initiative in the tourism service industry, organizational performance is directly affected.

Travel agency employee role stress leads to a reduction in the employee's organizational citizenship behavior $[4,55]$. Studies have also shown that when employees have fewer role conflicts, they perform well in terms of organizational citizenship behavior [56-59]. When organizational citizenship behavior is strong, employee role ambiguity decreases [60]. Role stress reduces employees' organizational citizenship behavior. In travel agencies, if employees fail to clearly understand their job responsibilities, personal permissions, and role sender expectations, role stress occurs, which negatively impacts psychology when working and leads to reductions in spontaneous behavior. Therefore, we inferred that role conflict and ambiguity impact organizational citizenship behavior and came up with the following hypotheses (the research model is shown in Figure 1).

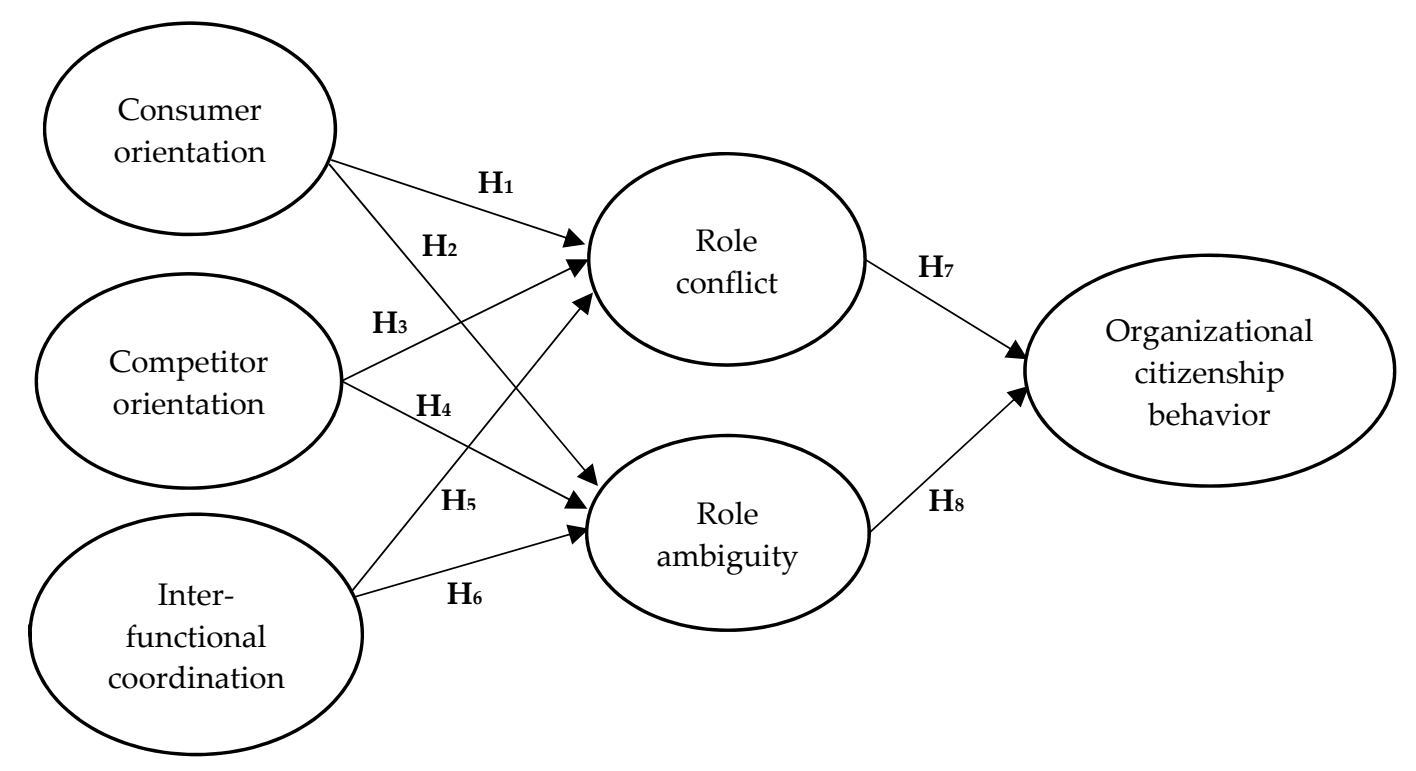

Figure 1. Research Model.

Hypothesis 7: Travel agency employee role conflict negatively impacts organizational citizenship behavior.

Hypothesis 8: Travel agency employee role ambiguity negatively impacts organizational citizenship behavior.

\section{Methodology}

\section{Data Collection}

We investigated the impact of relationships among market orientation toward travel agencies, role stress, and organizational citizenship behavior. A multiple-item scale was used for all variables, which used the validated instruments derived from a pilot study and rewritten to measure the factors influencing practitioners' behavior in travel agencies. Then, two professionals were asked to formulate a double translation protocol to develop a survey questionnaire and two tourism management professors amended the contents. A total of 50 practitioners in travel agencies evaluated the face and content validity of the Chinese version, which resulted in the rewording of some items. A total of 500 questionnaires were issued to class-A travel agencies and consolidated travel agencies in north, central, and south Taiwan as representative samplings. Invalid questionnaires, such as those with incomplete answers, were excluded from the 245 questionnaires that were completed and returned. The sample is described in Table 1. 
Table 1. Demographic Information $(n=245)$.

\begin{tabular}{cccc}
\hline Variables & Categories & $\boldsymbol{n}$ & $\%$ \\
\hline \multirow{2}{*}{ Gender } & Male & 128 & $52 \%$ \\
& Female & 117 & $48 \%$ \\
& Less than 24 & 13 & $5 \%$ \\
Age & $25-29$ & 41 & $17 \%$ \\
& $30-39$ & 63 & $26 \%$ \\
& $40-49$ & 50 & $20 \%$ \\
Marriage & $50-59$ & 51 & $21 \%$ \\
& Over 60 & 27 & $11 \%$ \\
Education & Yes & 156 & $64 \%$ \\
& No & 89 & $36 \%$ \\
& Senior High School & 49 & $20 \%$ \\
Seniority & College & 153 & $62 \%$ \\
& Above Graduate School & 43 & $18 \%$ \\
& Under 1 year & 12 & $5 \%$ \\
& $1-5$ years & 54 & $22 \%$ \\
& $6-10$ years & 69 & $28 \%$ \\
& $10-15$ years & 60 & $25 \%$ \\
Area & Over 16 years & 50 & $20 \%$ \\
& North Area & 107 & $44 \%$ \\
& Central Area & 77 & $31 \%$ \\
& South Area & 61 & $25 \%$ \\
\hline
\end{tabular}

The measures for this research were adapted from a literature review on related topics. The measurements from related studies were used for the variables in this study, with minor wording changes. Thus, we identified 23 possible research areas: four indicators for customer orientation, four for competitor orientation, three for inter-functional coordination [37], four indicators for role conflict and four indicators for role ambiguity [38], and four indicators for organizational citizenship behavior [61]. Seven-point Likert scales were used, ranging from highly disagree to highly agree (refer to the Appendix A, Table A1).

\section{Analysis and Results}

SmartPLS-3 was used to conduct partial least squares (PLS) analysis. The main advantages of PLS Structural Equation Modeling (SEM) include relaxing normal distribution assumptions required to estimate the model's maximum likelihood method using CB covariance-based (CB)SEM and the ability to forecast more complicated models using smaller samples [62-64]. We used SmartPLS-3 to investigate assessments as well as the hypotheses. In the process of bootstrap re-sampling, stable estimation was assessed. Two stages were analyzed and interpreted using the PLS model. PLS can measure item reliability and convergent as well as discriminant validities. Reliability and validity were first evaluated in the model followed by the test structural model. These procedures confirmed that the constructs were effective and trustworthy before making conclusions about their relationship.

\subsection{Measurement Model}

Evaluating each item factor loading determines item reliability. Values should have at least 0.6 to indicate high reliability, whereas values under 0.5 should be ignored $[65,66]$. After performing a statistical analysis, the loadings of all indicators of the consumer orientation, competitor orientation, and inter-functional coordination ranged from 0.74 to 0.91 , the role conflict and role ambiguity loading ranged from 0.61 to 0.91 , and the loading value of organizational citizenship behavior ranged from 0.78 to 0.84 . All of these values were above 0.5 , which indicated high reliability and are shown in Table 2 . 
Table 2. The distribution of loadings and correlations for each factor.

\begin{tabular}{cccc}
\hline Factor & Item & Loading & $\mathbf{t}$ \\
\hline & CO1 & 0.89 & 54.26 \\
Consumer Orientation & CO2 & 0.87 & 46.22 \\
(CO) & CO3 & 0.89 & 47.49 \\
& CO4 & 0.74 & 20.62 \\
Competitor Orientation & CPO1 & 0.91 & 17.13 \\
(CPO) & CPO2 & 0.90 & 57.93 \\
& CPO3 & 0.89 & 57.49 \\
Inter-Functional Coordination & CPO4 & 0.77 & 45.25 \\
(IFC) & IFC1 & 0.79 & 20.05 \\
& IFC2 & 0.77 & 33.82 \\
Role Conflict & IFC3 & 0.87 & 40.79 \\
(RC) & RC1 & 0.84 & 29.95 \\
& RC2 & 0.91 & 78.85 \\
Role Ambiguity & RC3 & 0.61 & 8.63 \\
(RA) & RC4 & 0.89 & 43.43 \\
& RA1 & 0.77 & 16.41 \\
& RA2 & 0.76 & 26.84 \\
& RA3 & 0.67 & 13.67 \\
Organizational Citizenship Behavior & RA4 & 0.67 & 8.61 \\
(OCB) & OCB1 & 0.81 & 28.19 \\
& OCB3 & 0.80 & 30.79 \\
& OCB4 & 0.84 & 25.45 \\
& & & 17.71 \\
\hline
\end{tabular}

To test the convergent validity, it is essential to evaluate reliability, compounding reliability, and the average variance extracted (AVE) for each construct. In addition, diverse indicators testing only one construct should be confirmed $[67,68]$. Construct reliability is usually assessed by Cronbach's $\alpha[69,70]$. The composite reliability of constructs results from squaring the sum of loadings and multiplying consolidation of the sum of squared loading and the error terms. Compared with differences between other variables, discriminant validity provides certain standards. AVE impacts the variance captured by indicators. A single indicator and a construct's validity are questioned when the value is less than 0.5 [71], and the value of Cronbach's $\alpha$ should be higher than 0.6 . After performing a statistical analysis, in this research, the Cronbach's $\alpha$ value of each construct ranged from 0.7 to 0.89 , and AVE ranged from 0.52 to 0.76 . Therefore, these values show reliability and validity and are presented in Table 3 .

Table 3. Reliabilities and variances.

\begin{tabular}{lccc}
\hline \multicolumn{1}{c}{ Construct } & Composite Reliability & Variance & Cronbach's Alpha \\
\hline Consumer Orientation & 0.91 & 0.72 & 0.87 \\
Competitor Orientation & 0.93 & 0.76 & 0.89 \\
Inter-functional Coordination & 0.85 & 0.66 & 0.74 \\
Role Conflict & 0.88 & 0.67 & 0.83 \\
Role Ambiguity & 0.81 & 0.52 & 0.70 \\
Organizational Citizenship Behavior & 0.90 & 0.65 & 0.82 \\
\hline
\end{tabular}

Compared with differences in the other variables, discriminant validity presents the degree. The AVE should be larger than the variance between the latent constructs in the model to determine validity $[72,73]$. As factor loading occurs on a single construct, procedures were used to determine cross-loading values. To check the discriminant validity, cross-loading must first present all indicators with greater loadings under the defined construct. Secondly, the correlation between pairs should be less than 0.9 . 
In this study, the factor loadings of each construct were found to be higher than the other constructs after statistical analysis. Therefore, this study means that it has reached the above indicators in numerical values. Finally, the square root of the AVE must be higher than its relationship with the constructs $[74,75]$. The square roots of each construct's AVE in this study were higher than the other constructs, and the correlations among the constructs were all well below the 0.85 threshold and therefore meet the measurement indicators of discrimination validity and are shown in Table 4.

Table 4. Descriptive statistics.

\begin{tabular}{cccccccccc}
\hline & Mean & S. D & CO & CPO & IFC & RC & RA & OCB & AVE \\
\hline Consumer Orientation & 6.01 & 0.67 & $\mathbf{( 0 . 8 5 )}$ & & & & & & 0.72 \\
Competitor Orientation & 6.22 & 0.62 & 0.43 & $\mathbf{( 0 . 8 7 )}$ & & & & & 0.76 \\
Inter-Functional Coordination & 6.14 & 0.61 & 0.41 & 0.36 & $\mathbf{( 0 . 8 1 )}$ & & & & 0.66 \\
Role Conflict & 1.90 & 0.58 & -0.50 & -0.51 & -0.77 & $\mathbf{( 0 . 8 2 )}$ & & & 0.67 \\
Role Ambiguity & 2.34 & 0.70 & -0.49 & -0.61 & -0.58 & 0.71 & $\mathbf{( 0 . 7 2 )}$ & & 0.52 \\
Organizational Citizenship Behavior & 6.29 & 0.57 & 0.47 & 0.50 & 0.72 & -0.76 & -0.59 & $\mathbf{( 0 . 8 1 )}$ & 0.65 \\
\hline
\end{tabular}

With consideration of the variance inflation factor (VIF), when a VIF achieves a value greater than 3.3, this indicates pathological collinearity [76]. The present model has a maximum VIF of 2.07, revealing that the research model had no collinearity problems.

\subsection{Structural Model}

To evaluate the structural pattern, the path coefficients, which represent the power of correlations focused on dependent and independent variables, must be estimated. Accordingly, the value of $R^{2}$ illustrates the measurements of variance explained by the independent variables. To obtain t-statistics and standard errors, a bootstrap re-sampling method was used as a confidence estimation process, which differs from approximation normally. $R^{2}$ is a powerful predictor and can be explained under multiple regressions.

The results of this study show that market orientation, customer orientation, competitor orientation, and inter-function coordination had negative impact relationships with role conflicts $\left(\mathrm{H}_{1}: \mathrm{t}=2.644\right.$, $\left.p<0.01 ; \mathrm{H}_{3}: \mathrm{t}=4.200, p<0.001 ; \mathrm{H}_{5}: \mathrm{t}=14.039, p<0.001\right)$ and role ambiguity $\left(\mathrm{H}_{2}: \mathrm{t}=2.893, p<0.01\right.$; $\left.\mathrm{H}_{4}: \mathrm{t}=6.900, p<0.001 ; \mathrm{H}_{6}: \mathrm{t}=6.395, p<0.001\right)$; role conflicts and organizational citizenship behavior also showed a negative influence relationship $\left(\mathrm{H}_{7}: \mathrm{t}=11.564, p<0.001\right)$. Table 5 and Figure 2 present the coefficients related to the path analysis. Hypotheses 1 to 7 were supported.

Table 5. Hypotheses testing.

\begin{tabular}{ccccc}
\hline & Hypothesis & Path Coefficients & t-Value & $p$ Values \\
\hline $\mathrm{H}_{1}$ & Consumer orientation $\rightarrow$ Role conflict & -0.146 & 2.644 & 0.008 \\
$\mathrm{H}_{2}$ & Consumer orientation $\rightarrow$ Role ambiguity & -0.169 & 2.893 & 0.004 \\
$\mathrm{H}_{3}$ & Competitor orientation $\rightarrow$ Role conflict & -0.220 & 4.200 & 0.000 \\
$\mathrm{H}_{4}$ & Competitor orientation $\rightarrow$ Role ambiguity & -0.409 & 6.900 & 0.000 \\
$\mathrm{H}_{5}$ & Inter-functional coordination $\rightarrow$ Role conflict & -0.634 & 14.039 & 0.000 \\
$\mathrm{H}_{6}$ & Inter-functional coordination $\rightarrow$ Role ambiguity & -0.361 & 6.395 & 0.000 \\
$\mathrm{H}_{7}$ & Role conflict $\rightarrow$ Organizational citizenship behavior & -0.698 & 11.564 & 0.000 \\
$\mathrm{H}_{8}$ & Role ambiguity $\rightarrow$ Organizational citizenship behavior & -0.088 & 1.380 & 0.168 \\
\hline
\end{tabular}




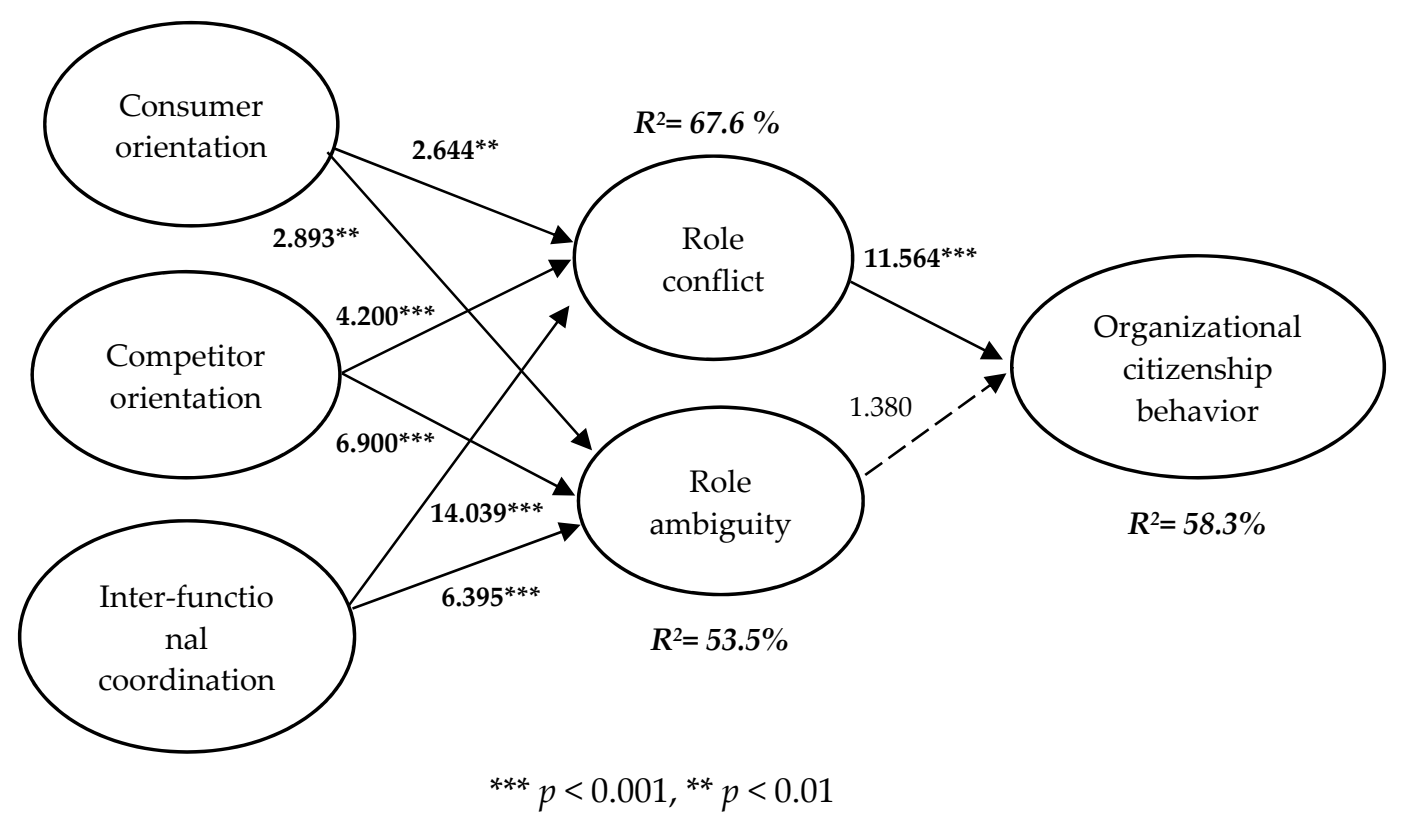

Figure 2. Hypotheses testing.

\section{Conclusions and Implications}

In this study, we examined the impact relationships of market orientation, role stress, and organizational citizenship behavior. To develop human resource management in travel agencies, the results showed that travel agencies should strongly adopt market orientation, which can decrease employee pressure, thus improving the organizational citizenship behavior of the enterprise. The proposed research model is a trustworthy tool for operationalizing the main constructs when analyzing practitioner behavior in travel agencies. The analysis of the measurements of the model showed that the proposed measurements are valid and reliable. Therefore, these measurements can be used to study the constructs and factors that affect practitioner behavior in travel agencies. Maximizing the benefits of sustainable tourism operations can also be used as a basic model and be applied to different industries.

\subsection{Theoretical Implications}

The findings prove the influence of the relationships among market orientation, role stress, and organizational citizenship behavior. First, we confirmed that customer orientation, competitor orientation, and inter-functional coordination considerably affect correlations between role conflict and role ambiguity. The higher the customer orientation, competitor orientation, and inter-functional coordination, the lower the role conflict and ambiguity are, providing the theoretical basis for the correlation of market orientation with role stress. Second, the results confirmed that role conflict negatively impacts organizational citizenship behavior. The fewer the role conflicts, the higher the organizational citizenship behavior. In contrast to our research expectations, role ambiguity was found to have no significant impact on organizational citizenship behavior, showing that even if employees feel uncertain about the tasks they are assigned, it may not initially affect their contributions to the organization. Finally, according to the above results, we found that the model of market orientation, role stress (role conflict), and organizational citizenship behavior impacts organizations.

Therefore, in terms of research application, we constructed an influence model of market orientation, role stress, and organizational citizenship behavior. The results showed that market orientation significantly influences role stress and role conflict as well as organizational citizenship behavior. Explorations of the relationship between negative factors and organizational citizenship behavior were previously lacking. We also confirmed that a negative impact relationship exists between role conflict and organizational citizenship behavior. The results add to the research on negative factors 
and organizational citizenship behavior. Finally, the results improve the integrity of human resource theories and provide reference for further study.

\subsection{Practical Implications}

The research confirmed the influencing impact relationships among market orientation, role stress, and organizational citizenship behavior. The results provide a basis for further practical strategic formulation for travel agencies. Firstly, for the relationship among customer orientation, role conflicts, and role ambiguities, travel agencies can improve customer orientation to help employees clearly focus on assigned tasks to reduce the effects of the subjective factors on employees and their objective cognitions to lower role stress, enabling travel agencies to focus on providing customers with value and satisfaction. Travel agencies can adopt a highly competitor-oriented strategy so that employees fully understand competitor information and activities and promote the development of high-level management strategies to respond quickly to competitors' activities. Another strategy involves adopting a high degree of inter-functional coordination and strengthening the cooperation and communication mechanism between employees and departments to reduce task uncertainty and conflicts, thereby improving the effectiveness of the enterprise.

Second, when travel agencies reduce employee role stress (conflict), they can promote organizational citizenship behavior through the establishment of an organizational climate and other mechanisms that become part of the organizational culture. Taiwan's travel agencies are mostly small- and medium-sized enterprises, which lack training systems and other human resource management mechanisms. Organizational citizenship behavior creates positive interactions and learning opportunities between employees of the organization so that the organization can achieve sustainable development and gain a competitive advantage.

Finally, market orientation is one of the strategies through which a travel agency can create a competitive advantage and achieve sustainable development. Enterprises should build a market-oriented business model to promote the formation of organizational culture, so that each employee has a clear understanding of the enterprise's goals and directions with a view to reduce role conflict and ambiguity. This strategy creates more positive opportunities for cooperation and communication within the enterprise and, via mutual assistance to improve team cohesion, the formation of enterprise learning organizations can be enhanced, fostering competitive advantages and achieving sustainable management.

\subsection{Limitations}

In this research, it was hard to obtain samples, and the sample used to verify the research structure was small. Travel agencies in Taiwan are mostly small- and medium-sized enterprises and the enterprise culture for each country is different. Therefore, the results may not be applicable to travel agencies from other countries or regions.

This research framework can be used to verify the impact relationship in other industries and to further understand the research and growth of human-resources management used in tourism.

Finally, although we found no significant correlations among role ambiguity and organizational citizenship behavior, future research could verify the relationship between the two factors or understand whether a mediator exists between them.

Author Contributions: Research structure and construction, L.H. and K.-Y.C.; literature data analysis and collections, K.-Y.C.; sampling and survey, K.-Y.C.; research design and methodology, L.H. and K.-Y.C.; conclusions and suggestions, L.H. and K.-Y.C.; research progress controller and supervisor, L.H.; writing-review and editing, L.H., K.-Y.C., and Y.-C.Y. All authors have read and agreed to the published version of the manuscript.

Funding: No external funding has received in this research.

Conflicts of Interest: No conflict interest is declared by the authors. 


\section{Appendix A Scale Development}

Table A1. Scale development.

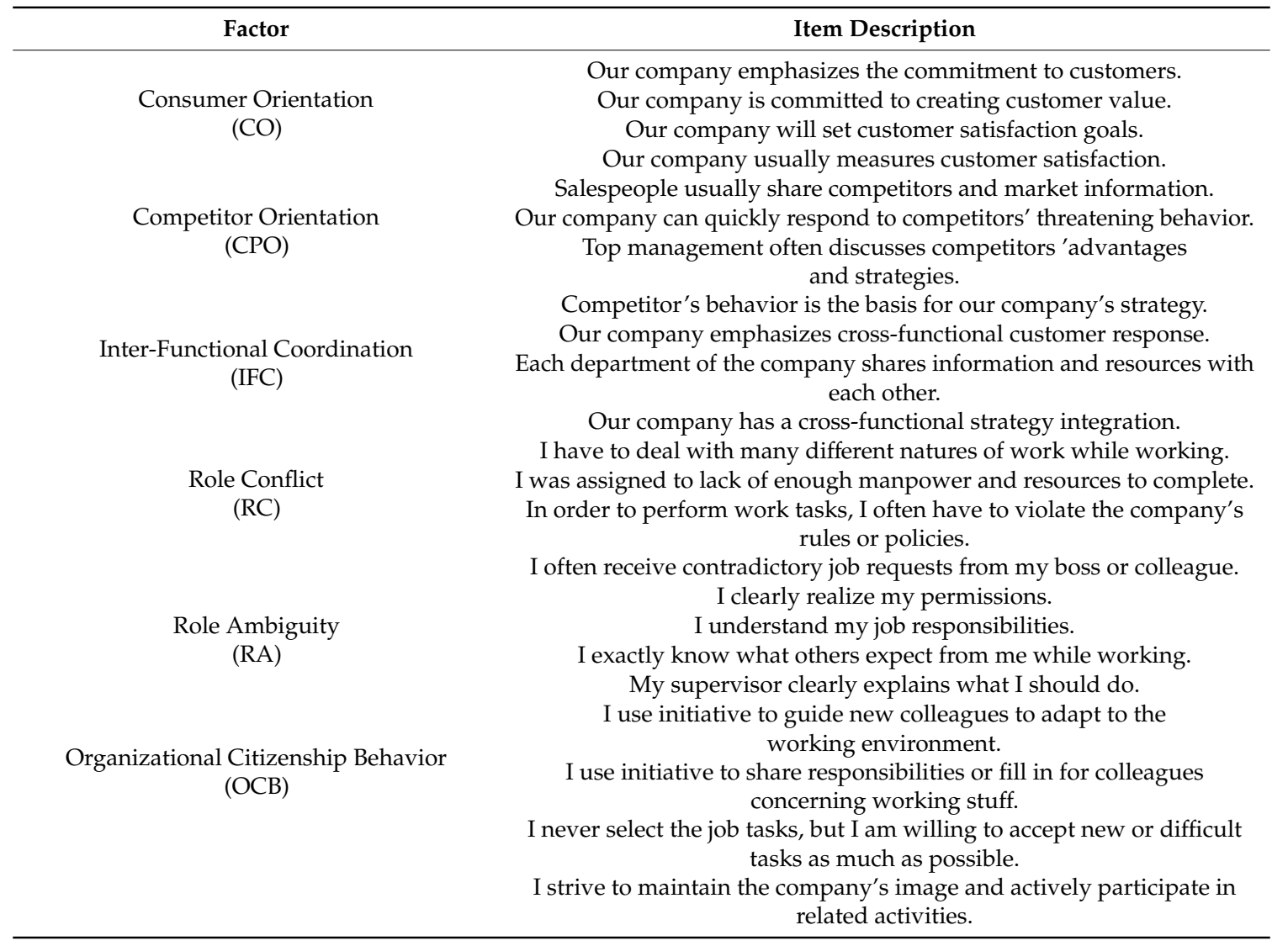

\section{References}

1. Hu, H.H.; Hu, H.Y.; King, B. Impacts of misbehaving air passengers on frontline employees: Role stress and emotional labor. Int. J. Contemp. Hosp. Manag. 2017, 29, 1793-1813. [CrossRef]

2. Sawitri, D.; Endang, S.; Khasbulloh, H. The Impact of Job Satisfaction, Organization Commitment, Organization Citizenship Behaviour (OCB) on Employees Performance. Int. J. Organ. Innov. 2016, 9, 24-45.

3. Callea, A.; Urbini, F.; Chirumbolo, A. The mediating role of organizational identification in the relationship between qualitative job insecurity, OCB and job performance. J. Manag. Dev. 2016, 35, 735-746. [CrossRef]

4. Chahal, H.; Mehta, S. antecedents and consequences of organizational citizenship behavior: A conceptual framework in reference to health care sector. J. Serv. Res. 2011, 10, 25-44.

5. Adeleke, O.B.; Jianguo, D. When the good outweighs the bad: Organizational citizenship behavior in the workplace. Hum. Resour. Dev. Int. 2020, 23, 88-97.

6. Kazemian, S.; Abdul Rahman, R.; Mohd, S.Z.; Adewale, A. Role of market orientation in sustainable performance: The case of a leading microfinance provider. Humanomics 2016, 32, 352-375. [CrossRef]

7. Schwepker, C.; Ingram, T. Ethical leadership in the salesforce: Effects on salesperson customer orientation, commitment to customer value and job stress. J. Bus. Ind. Mark. 2016, 31, 914-927. [CrossRef]

8. Zablah, A.R.; Franke, G.R.; Brown, T.J.; Bartholomew, D.E. How and When Does Customer Orientation Influence Frontline Employee Job Outcomes? A Meta-Analytic Evaluation. J. Mark. 2012, 76, 21-40. [CrossRef]

9. Andersson, L.M.; Bateman, T.S. Cynicism in the workplace: Some causes and effects. J. Organ. Behav. 1997, 18, 449-469. [CrossRef] 
10. Wayne, A.H.; Christian, K.; Michael, J.G.; Jason, S. The Impact of Vocational and Social Efficacy on Job Performance and Career Satisfaction. J. Leadersh. Organ. Stud. 2004, 10, 27-40.

11. Turner, J.H.; Valentine, S.R. Cynicism as fundamental dimension of moral decision-making: A scale development. J. Bus. Ethics 2001, 34, 123-136. [CrossRef]

12. Lin, C.C. The Effect of Role Stress on the relationship between Internal Marketing and Customer-oriented Behavior: The Case of Food Service in Taiwan"s International Tourist Hotels. Unpublished. Master Thesis, National Chiayi University, Chiayi, Taiwan, 2001.

13. Hurley, R.F.; Hult, G.T.M. Innovation, market orientation, and organizational learning: An integration and empirical examination. J. Mark. 1998, 62, 42-54. [CrossRef]

14. Hunt, S.D.; Morgan, R.M. The resource advantage theory of competition: Dynamics, path dependencies, and evolutionary dimensions. J. Mark. 1996, 60, 107-114. [CrossRef]

15. Slater, S.F.; Narver, J.C. Customer-led and market-oriented: Let's not confuse the two. Strateg. Manag. J. 1998, 19, 1001-1006. [CrossRef]

16. Chen, C.F.; Myagmarsuren, O. Exploring the moderating effects of value offerings between market orientation and performance in tourism industry. Int. J. Tour. Res. 2013, 15, 595-610. [CrossRef]

17. Herrero, A.; San, M.H.; Collado, J. Market orientation and SNS adoption for marketing purposes in hospitality microenterprises. J. Hosp. Tour. Manag. 2018, 34, 30-40. [CrossRef]

18. Hill, C.W.L.; Jones, G.R. Strategic Management: An Integrated Approach; Houghton Mifflin: Boston, MA, USA, 1998.

19. Lukas, B.A. Strategy Type, Market Orientation, and the Balance Between Adaptability and Adaptation. J. Bus. Res. 1999, 45, 147-156. [CrossRef]

20. Qu, R. Market Orientation and Organizational Performance Linkage in Chinese Hotels: The Mediating Roles of Corporate Social Responsibility and Customer Satisfaction. Asia Pac. J. Tour. Res. 2014, 19, 1399-1416. [CrossRef]

21. Prifti, R.; Alimehmeti, G. Market orientation, innovation, and firm performance-An analysis of Albanian firms. J. Innov. Entrep. 2017, 6, 8. [CrossRef]

22. Bader, Y.O. The Effect of Strategic Orientation on Organizational Performance: The Mediating Role of Innovation. Int. J. Commun. Netw. Syst. Sci. 2016, 9, 478-505.

23. Day, G.S. The Capabilities of Market-Driven. Organizations. J. Mark. 1994, 58, 37-52. [CrossRef]

24. Kaur, G.; Gupta, M.C. A perusal of extant literature on market orientation-Concern for its implementation. Mark. Rev. 2010, 10, 87-105. [CrossRef]

25. Kahn, R.L.; Wolfe, D.M.; Quinn, R.P.; Snoke, J.D.; Rosenthal, R.A. Organizational Stress: Studies in Role Conflict and Ambiguity; John Wiley: New York, NY, USA, 1964.

26. Dubinsky, A.B.; Mattson, R.E.; Michaels, M.; Kotabe, C.U.; Lim, H.M. Influence of Role Stress on Industrial Salespeople's Work Outcomes in the United States, Japan, and Korea. J. Int. Bus. Stud. 1992, 23, 77-100. [CrossRef]

27. Kim, B.P.; Murrmann, S.K.; Lee, G. Moderating effects of gender and organizational level between role stress and job satisfaction among hotel employees. Int. J. Hosp. Manag. 2009, 28, 612-619. [CrossRef]

28. Van, S.M.; Brief, A.P.; Schuler, R.S. Role conflict and role ambiguity: Integration of the literature and directions for future research. Hum. Relat. 1981, 34, 43-71.

29. Jang, J.; George, R.T. Understanding the influence of polychronicity on job satisfaction and turnover intention: A study of non-supervisory hotel employees. Int. J. Hosp. Manag. 2012, 31, 588-595. [CrossRef]

30. McCarthy, C.J.; Lambert, R.G.; Reiser, J. Vocational Concerns of Elementary Teachers: Stress, Job Satisfaction, and Occupational Commitment. J. Employ. Couns. 2014, 51, 59-74. [CrossRef]

31. Akgunduz, Y. The influence of self-esteem and role stress on job performance in hotel businesses. Int. J. Contemp. Hosp. Manag. 2015, 27, 1082-1109. [CrossRef]

32. McGrath, J.E. Stress and Behavior in Organizations. In Handbook of Industrial and Organizational Psychology; Dunnette, M.S., Ed.; Rand McNally College Pub.: Chicago, IL, USA, 1976.

33. Dursun, T.; Kilic, C. The Effect of Market Orientation on New Product Performance: The Role of Strategic Capabilities. Acad. Mark. Stud. J. 2015, 19, 169.

34. Powpaka, S. How market orientation affects female service employees in Thailand. J. Bus. Res. 2006, 59, 54-61. [CrossRef] 
35. Tosi, H.L.; Rizzo, J.R.; Carroll, S.J. Management Organizational Behavior; Blackwell Publishers: Hoboken, NJ, USA, 1994.

36. Knight, D.; Kim, H.; Crutsinger, C. Examining the effects of role stress on customer orientation and job performance of retail salespeople. Int. J. Retail Distrib. Manag. 2007, 35, 381-392. [CrossRef]

37. Narver, J.C.; Slater, S.F. The effect of a market orientation on business profitability. J. Mark. 1990, 54, $20-35$. [CrossRef]

38. Chang, W.L.; Lu, L.C.; Su, H.J.; Lin, T.A.; Chang, K.Y. The Mediating Effect of Role Stressors on Market Orientation and Organizational Commitment. Soc. Behav. Personal. Int. J. 2010, 38, 1431-1440. [CrossRef]

39. Babin, B.J.; Boles, J.S. Employee behavior in a service environment: A model and test of potential differences between men and women. J. Mark. 1998, 62, 77-91. [CrossRef]

40. Katz, D.; Kahn, R.L. The social psychology of organizations; Wiley: New York, NY, USA, 1978.

41. Blau, P. Exchange and Power in Social Life; Wiley: New York, NY, USA, 1964.

42. Robinson, S.L.; Morrison, E.W. Psychological contracts and OCB: The effect of unfulfilled obligations on civic behavior. J. Organ. Citizsh. Behav. 1995, 16, 289-298. [CrossRef]

43. Robbins, S.P. Organizational Behavior; Prentice-Hall: Upper Saddle River, NJ, USA, 1996.

44. Dyne, L.V.; Graham, J.G.; Dienesch, R.M. Organizational Citizenship Behavior: Construct Redefinition, Measurement, and Validation. Acad. Manag. J. 1994, 37, 765-802.

45. Katz, D. The motivational basis of organizational behavior. Behav. Sci. 1964, 9, 131-146. [CrossRef]

46. Tang, T.W.; Tang, Y.Y. Promoting service-oriented organizational citizenship behaviors in hotels: The role of high-performance human resource practices and organizational social climates. Int. J. Hosp. Manag. 2012, 31, 885-895. [CrossRef]

47. Shih, C.; Chuang, C. Individual differences, psychological contract breach, and organizational citizenship behavior: A moderated mediation study. Asia Pac. J. Manag. 2013, 30, 191-210. [CrossRef]

48. Agarwal, U.A.; Datta, S.; Blake, B.S.; Bhargava, S. Linking LMX, innovative work behaviour and turnover intentions: The mediating role of work engagement. Career Dev. Int. 2012, 17, 208-230. [CrossRef]

49. Tziner, A.; Sharoni, G. Organizational citizenship behavior, organizational justice, job stress, and workfamily conflict: Examination of their interrelationships with respondents from a non-Western culture. Rev. De Psicol. Del Trab. Y De Las Organ. 2014, 30, 35-42. [CrossRef]

50. Lin, C.C.; Shiao, S.Y.; Ho, W.C. Relationship among Organizational Support, Knowledge Sharing and Citizenship Behaviors Based on the Perspective of Social Exchange Theory: Viewpoints of Trust and Relationship. J. Hum. Resour. Manag. 2003, 5, 77-110.

51. Xie, Z.T.; Xinmin, Z.J. Impact of Transformational Leadership's on Employee Organizational Citizenship Behavior: Examing A Multiple-Mediation Model. Sci. Sci. Manag. 2010, 3, 67-72.

52. Lu, H.; Yue, A.; Han, Y.; Chen, H. Exploring the Effect of Different Performance Appraisal Purposes on Miners' Organizational Citizenship Behavior: The Mediating Role of Organization Identification. Sustainability 2018, 10, 4254. [CrossRef]

53. Deepa, E.; Palaniswamy, R.; Kuppusamy, S. Effect of performance appraisal system in organizational commitment, job satisfaction and productivity. J. Contemp. Manag. Res 2014, 8, 72.

54. Redman, T.; Snape, E. The consequences of dual and unilateral commitment to the organisation and union. Hum. Resour. Manag. J. 2016, 26, 63-83. [CrossRef]

55. Hamsani, H.; Valeriani, D.; Zukhri, N. Work Status, Satisfaction and Organizational Citizenship Behavior: A Case Study on Bangka Islamic Bank. Prov. Bangka Belitung Int. Rev. Manag. Mark. 2019, 9, 1-8.

56. Judge, T.A.; Colquitt, J.A. Organizational justice and stress: The mediating role of work-family conflict. J. Appl. Psychol. 2004, 89, 395-404. [CrossRef]

57. Moorman, R.H. Relationship between organizational justice and organizational citizenship behaviors: Do fairness perceptions influence employee citizenship? J. Appl. Psychol. 1991, 76, 845. [CrossRef]

58. Brian, P.N.; Robert, H.M. Justice as a Mediator of the Relationship Between Methods of Monitoring and Organizational Citizenship Behavior. AMJ 1993, 36, 527-556.

59. Paul, E.S.; Xin, X.C. Re-examining Citizenship: How the Control of Measurement Artifacts Affects Observed Relationships of Organizational Citizenship Behavior and Organizational Variables. Hum. Perform. 2014, $27,165-182$.

60. Leigang, Z.; Huaibin, J.; Tingting, J. Leader-member exchange and organisational citizenship behaviour: The mediating and moderating effects of role ambiguity. J. Psychol. Afr. 2020, 30, 17-22. 
61. Farh, J.P.; Christopher, E.; Lin, S.C. Impetus for Action: A Cultural Analysis of Justice and Organizational Citizenship Behavior in Chinese Society. Adm. Sci. Q. 1997, 42, 421-444. [CrossRef]

62. Hair, J.F.; Risher, J.J.; Sarstedt, M.; Ringle, C.M. When to use and how to report the results of pls-sem. Eur. Bus. Rev. 2019, 31, 2-24. [CrossRef]

63. Cheah, J.H.; Sarstedt, M.; Ringle, C.M.; Ramayah, T.; Ting, H. Convergent validity assessment of formatively measured constructs in pls-sem: On using single-item versus multi-item measures in redundancy analyses. Int. J. Contemp. Hosp. Manag. 2018, 30, 3192-3210. [CrossRef]

64. Khan, G.F.; Sarstedt, M.; Shiau, W.-L.; Hair, J.F.; Ringle, C.M.; Fritze, M.P. Methodological research on partial least squares structural equation modeling (pls-sem): An analysis based on social network approaches. Internet Res. 2019, 29, 407-429. [CrossRef]

65. Tenenhaus, M.; Vinzi, V.E.; Chatelin, Y.-M.; Lauro, C. Pls path modeling. Comput. Stat. Data Anal. 2005, 48, 159-205. [CrossRef]

66. Wetzels, M.; Odekerken-Schröder, G.; Van Oppen, C. Using pls path modeling for assessing hierarchical construct models: Guidelines and empirical illustration. MIS Q. 2009, 33, 177-195. [CrossRef]

67. Hulland, J. Use of partial least squares (pls) in strategic management research: A review of four recent studies. Strateg. Manag. J. 1999, 20, 195-204. [CrossRef]

68. Fornell, C.; Larcker, D.F. Evaluating structural equation models with unobservable variables and measurement error. J. Mark. Res. 1981, 18, 39-50. [CrossRef]

69. Bagozzi, R.P.; Yi, Y. On the evaluation of structural equation models. J. Acad. Mark. Sci. 1988, 16, 74-94. [CrossRef]

70. Cortina, J.M. What is coefficient alpha? An examination of theory and applications. J. Appl. Psychol. 1993, 78, 98. [CrossRef]

71. Peterson, R.A. A meta-analysis of cronbach's coefficient alpha. J. Consum. Res. 1994, 21, 381-391. [CrossRef]

72. Hubert, M.; Engelen, S. Fast cross-validation of high-breakdown resampling methods for pca. Comput. Stat. Data Anal. 2007, 51, 5013-5024. [CrossRef]

73. Zhang, G.; Taniguchi, M. Discriminant analysis for stationary vector time series. J. Time Ser. Anal. 1994, 15, 117-126. [CrossRef]

74. Maharaj, E.A.; Alonso, A.M. Discriminant analysis of multivariate time series: Application to diagnosis based on ecg signals. Comput. Stat. Data Anal. 2014, 70, 67-87. [CrossRef]

75. Markham, I.S.; Ragsdale, C.T. Combining neural networks and statistical predictions to solve the classification problem in discriminant analysis. Decis. Sci. 1995, 26, 229-242. [CrossRef]

76. Kock, N. Common method bias in PLS-SEM: A full collinearity assessment approach. Int. J. E-Collab. 2015, 11, 1-10. [CrossRef]

(C) 2020 by the authors. Licensee MDPI, Basel, Switzerland. This article is an open access article distributed under the terms and conditions of the Creative Commons Attribution (CC BY) license (http://creativecommons.org/licenses/by/4.0/). 